\title{
Ultrahigh performance bio-based polyimides from 4,4'-
}

\section{diaminostilbene}

\author{
Amit Kumar ${ }^{1,3}$, Seiji Tateyama ${ }^{1,4}$, Katsuaki Yasaki ${ }^{1}$, Mohammad Asif Ali ${ }^{1}$, Naoki \\ Takaya $^{2,4}$, \\ Rajeev Singh ${ }^{3}$ and Tatsuo Kaneko*, 1,4 \\ ${ }^{1}$ School of Materials Science, Japan Advanced Institute of Science and Technology (JAIST), \\ 1-1 Asahidai, Nomi-shi, Ishikawa, 923-1292, Japan \\ ${ }^{2}$ Faculty of Life and Environmental Sciences, University of Tsukuba, Ibaraki, 305-8572, \\ Japan \\ ${ }^{3}$ Material/ Organometallics Laboratory, Department of Chemistry, ARSD College, University \\ of Delhi-110021, India \\ ${ }^{4}$ JST, ALCA
}

Equal contribution to this paper

*Email: kaneko@jaist.ac.jp, Telephone: +81-761-51-1633, Fax: +81-761-51-1635.

ABSTRACT: We have developed a novel route for the synthesis of high-performance biopolyimides (PIs) microbially-derived from photo-responsive aromatic diamine 4,4'diaminostilbene (DAS) and its reduced counterpart 4,4'-(ethane-1,2-diyl)dianiline (EDDA). DAS and EDDA were condensed with various commercially-available dianhydrides to obtain a series of poly(amic acid)s (PAAs) and PIs which were characterized in terms of their thermal, mechanical, and photo-functions. These bio-based PAAs showed a very high viscosity of $6.62 \mathrm{dL} / \mathrm{g}$, and the PIs showed ultrahigh thermal resistance with $T_{\mathrm{d} 10}$ values over $600{ }^{\circ} \mathrm{C}$, which were higher than that of any bio-based plastic reported thus far. They also showed $T_{\mathrm{g}}$ values above $250{ }^{\circ} \mathrm{C}$, and tensile strength of over $132 \mathrm{MPa}$, which is higher than that of Kapton ${ }^{\mathrm{TM}}$. The PIs also showed photo-functional behavior based on stilbene-based photoreactions.

(C) 2015. This manuscript version is made available under the Elsevier user license http://www.elsevier.com/open-access/userlicense/1.0/ 
KEYWORDS: stilbenes, polyimides, high performances, photofunctions, aromatic diamines.

\section{1.\#ntroduction}

Development of renewable polymer materials such as bio-based plastics is indispensable in the creation of a sustainable society ${ }^{[1]}$. Although bio-based polymers such as polyurethanes, polyesters, and polyamides have been synthesized using bio-available aliphatic molecules, however low thermal and mechanical properties restrict their application as high performance materials $^{[2-9]}$. High-performance plastics are in demand due to their exceptionally high thermal and mechanical properties that fulfill the requirements of various industrial applications such as their use in electronic insulation, automobiles parts, transportation and aviation materials ${ }^{[10]}$. Introduction of aromatic rings in the backbone of the polymer chain improves performance and we have prepared high-performance aromatic biopolyesters from phenolic acids ${ }^{[9]}$. However polyesters showed a fatal limitation of thermodegradation at around $300{ }^{\circ} \mathrm{C}$, which forced us to change the molecular design ${ }^{[5-12]}$.

We have reported polyimides (PIs), which are a special class of polymers with intrinsically high thermal and mechanical properties ${ }^{[13,14]}$, by bio-based aromatic diamines which had never been developed by bio-processing ${ }^{[15-17]}$.

In previous reports, an exotic aromatic amino acid, 4-aminocinnamic acid (4ACA), was produced using recombinant Escherichia coli from glucose via 4-aminophenylalanine $(4 \mathrm{APhe})^{[18-21]}$. 4ACA dimerization can give bio-based aromatic diamine monomers and then 4ACA photoreactivity was utilized to prepare photodimer, 4,4'-diaminotruxillic acid. However, the cyclobutane moiety of truxillate backbone is less thermally stable than an aromatic ring or double bond. Therefore, we tried to develop another 4ACA dimerization method by metathesis catalysis to produce stilbene ${ }^{[22-24]}$. 
In this report, we describe the novel synthetic route of 4,4'-diaminostylbene (DAS) and its derivative from bio-based 4ACA by utilizing Grubb's olefin metathesis as a key step. Then, we synthesized bio-based polyimides from DAS by reactions with different dianhydrides, which show excellent thermo-mechanical properties.

\section{Experimental Section}

\subsection{Materials}

4-aminocinnamic acid which was used for the synthesis of the diamine monomers preparation was obtained via two routes: 1) fermentation using genetically-manipulated Escherichia coli $^{[25]}$; and 2) purchase from TCI (Tokyo, Japan). Pyromellitic anhydride (PMDA) was purchased from Kanto Chemical Co. Inc. 3,3',4,4'-benzophenone tetracarboxylic dianhydride (BTDA), 3,3',4,4'-diphenylsulfone tetracarboxylic dianhydride (DSDA), 3,4,3', 4'- $^{\prime}$ biphenyltetracarboxylic dianhydride (BPDA), 4,4'-oxidiphthalic anhydride (OPDA), 1,2,3,4tetracarboxycyclobutane dianhydride (CBDA) and trimethylsilyl chloride (TMSCl) were purchased from Aldrich. N,N-dimethylacetamide (DMAc) (99.8\% anhydrous) was purchased from Kanto Chemical and was used as received. All of the dianhydrides were purified before using by refluxing with acetic anhydride for $6 \mathrm{~h}$, and cooling to $0-5{ }^{\circ} \mathrm{C}$. The crystals were carefully collected by filtration, washed in hot dioxane, and dried in vacuo.

\subsection{Instrumentation and Characterizations}

${ }^{1} \mathrm{H}$ nuclear magnetic resonance $\left({ }^{1} \mathrm{H}-\mathrm{NMR}\right)$ and ${ }^{13} \mathrm{C}-\mathrm{NMR}$ were performed on a Bruker Biospin AG 400 and $100 \mathrm{MHz}$ spectrometer respectively using DMSO- $d_{6}$ as a solvent at 23.1 ${ }^{\circ} \mathrm{C}$ with 16 accumulation scans, using the proton resonance of residual non-deuterated DMSO as an internal standard $(2.55 \mathrm{ppm})$. The FT-IR spectra were recorded with a Perkin-Elmer Spectrum One spectrometer between 4000 and $400 \mathrm{~cm}^{-1}$ using a diamond-attenuated total 
reflection (ATR) accessory. The mass spectra were measured using a Fourier transform ion cyclotron resonance mass spectrometer (FT-ICR MS, Solarix) and scanned from $\mathrm{m} / \mathrm{z} 50$ to $m / z$ 1000. The ultraviolet-visible (UV-vis) optical absorption spectra were recorded on a Perkin-Elmer Lambda $25 \mathrm{UV} /$ vis spectrophotometer at room temperature. The inherent viscosities were measured using an Ubbelohde viscometer at $30{ }^{\circ} \mathrm{C}$ in DMAc at a polymer concentration of $0.5 \mathrm{~g} / \mathrm{dL}$. Thermogravimetric analysis (TGA) and differential scanning calorimetry (DSC) were performed on Seiko Instruments SII, SSC/5200 and Seiko Instruments SII, X-DSC7000T, respectively, at a heating rate of $10^{\circ} \mathrm{C} / \mathrm{min}$ under a nitrogen atmosphere. The tensile measurements were carried out at an elongation speed of 0.5 $\mathrm{mm} / \mathrm{min}$ on a tensiometer (Instron 3365) at room temperature. The number-average molecular weight $\left(M_{\mathrm{n}}\right)$, weight-average molecular weight $\left(M_{\mathrm{w}}\right)$ and the molecular weight distribution (PDI) were determined by gel permeation chromatography (GPC; Shodex GPC101 with a connection column system of 803 and 807 , concentration $5 \mathrm{~g} / \mathrm{L}$, DMF eluant) after calibration with pullulan standards. The solubility of the polymers was investigated using 1 mg of sample in $1 \mathrm{~mL}$ of solvent at room temperature and at $50{ }^{\circ} \mathrm{C}$.

\subsection{Monomer syntheses}

\subsubsection{Syntheses of diamines}

The systematic representation of synthesis of DAS and its reduced counterparts 4,4'-(ethane1,2-diyl)dianiline (EDDA) from 4ACA is shown in Scheme $1 . \mathrm{cm}^{-1}$ 
A)

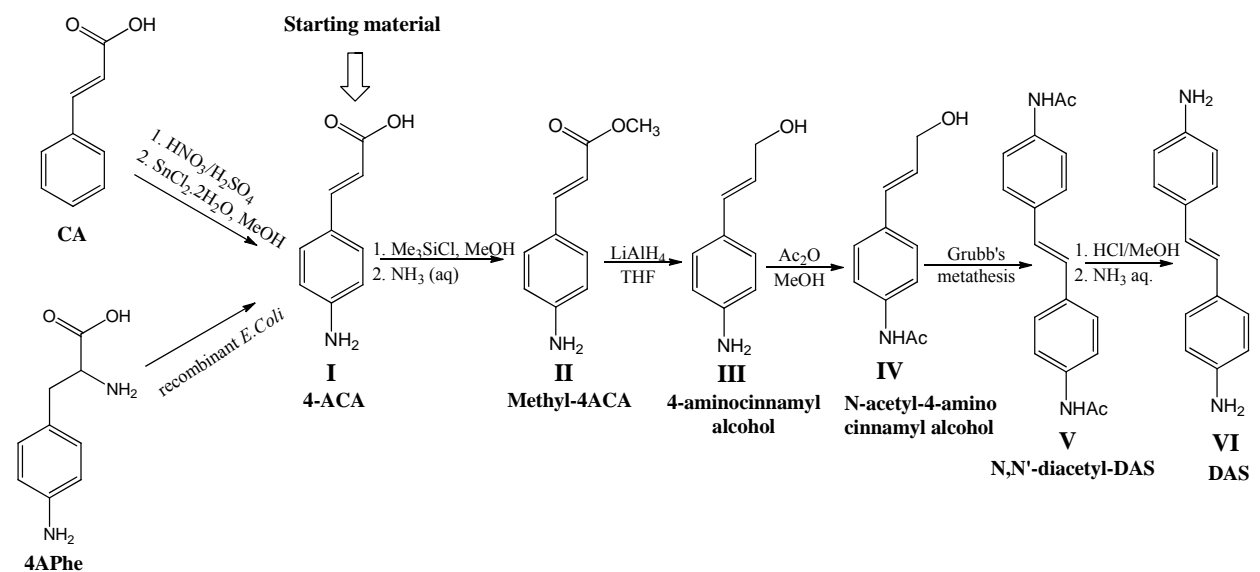

B)

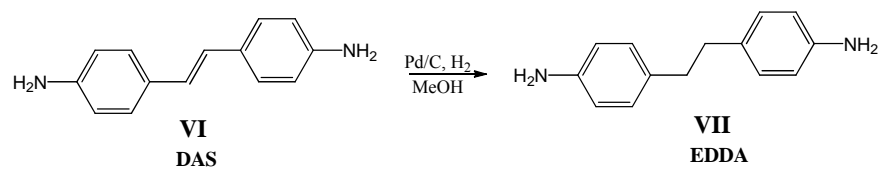

Scheme 1. Synthesis of DAS and EDDA monomers from 4ACA.

a) Preparation of methyl-4-aminocinnamic acid ester (methyl-4ACA) from 4ACA. 30 mmol of 4ACA $(5.00 \mathrm{~g}, 30.64 \mathrm{mmol})$ was mixed methanol $(50 \mathrm{ml})$ in a two neck flask round bottom flask under nitrogen, to obtain a mixture in suspended state. TMSCl $(6.2 \mathrm{~g} 7.6 \mathrm{~mL}, 60$ mmol) was added dropwise with constant stirring at room temperature. The mixture became clear after complete addition of TMSCl and after some time the solid started separating out. The mixture was stirred for $12 \mathrm{~h}$ at room temperature. The solvent was evaporated and crude sample was dried under vacuum. Thus prepared compound was treated with ammonia and the compound was extracted with ethyl acetate. The collecting ethyl acetate organic layer was dried over $\mathrm{MgSO}_{4}$, and it was then evaporated. Thus compound obtained was found to be methyl-4-ACA in $99 \%$ yield. The specifications were as follow: ${ }^{1} \mathrm{H}$ NMR (400 MHz, DMSO-d $\left._{6}, \delta, \mathrm{ppm}\right): 3.67(\mathrm{~s}, 3 \mathrm{H}), 5.78(\mathrm{~s}, 2 \mathrm{H}), 6.23(\mathrm{~d}, 1 \mathrm{H}, J=8 \mathrm{~Hz}), 6.56(\mathrm{~d}, 2 \mathrm{H} J=16 \mathrm{~Hz})$, $7.37(\mathrm{~d}, 2 \mathrm{H}, J=8 \mathrm{~Hz}), 7.47(\mathrm{~d}, 1 \mathrm{H} J=16 \mathrm{~Hz}) .{ }^{13} \mathrm{C}$ NMR $\left(100 \mathrm{MHz}, \mathrm{DMSO}-\mathrm{d}_{6}, \delta, \mathrm{ppm}\right)$ : 51.5, 111.0, 114.0, 121.7, 130.7, 146.0, 152.0, 167.9. Mass: $\mathrm{m} / z=178.08617$ (experimental), 177.0790 (calculated). Melting point: $129^{\circ} \mathrm{C}$ 
b) Preparation of 4-amino-cinnamyl alcohol from 4-aminomethylcinnamate. $\mathrm{LiAlH}_{4}(4.5$

g, $117.5 \mathrm{mmol})$ and anhydrous THF $(40 \mathrm{ml})$ was mixed in a two neck round bottom flask under nitrogen atmosphere. A solution of methyl-4-ACA (4.18 g, $23.5 \mathrm{mmol})$ in anhydrous THF $(20 \mathrm{ml})$ was slowly added into the $\mathrm{LiAlH}_{4} / \mathrm{THF}$ mixture. After complete addition the reaction mixture was stirred for 90 mins. The reaction was quenched by addition of ethanol and then water followed by the filtration. The compound was extracted by ethylacetate ( 40 ml) 3 times and the organic layer was dried over $\mathrm{MgSO}_{4}$, which was then evaporated. The crude compound was purified by column chromatography using silica and $10 \%$ ethylacetate/ petroleum ether as eluent. Compound thus obtained was found to be $60 \%$ yield (purity $>95$ \%) with some residual impurity which was eliminated during purification after acetylation of 4-aminocinnamyl alcohol. The specifications were as follow: ${ }^{1} \mathrm{H}$ NMR (400 MHz, DMSO- $\mathrm{d}_{6}$, $\delta$, ppm): $4.04(\mathrm{t}, 2 \mathrm{H}), 4.69(\mathrm{t}, \mathrm{OH}), 5.15(\mathrm{~s}, 2 \mathrm{H}), 6.01$ (td triplet of doublet) $1 \mathrm{H}, J=16 \mathrm{~Hz})$, $6.33(\mathrm{~d}, 1 \mathrm{H}, J=16 \mathrm{~Hz}), 6.50(\mathrm{~d}, 2 \mathrm{H} J=8 \mathrm{~Hz}), 7.08(\mathrm{~d}, 2 \mathrm{H}, J=8 \mathrm{~Hz}) .{ }^{13} \mathrm{C} \mathrm{NMR}(100 \mathrm{MHz}$, DMSO-d ${ }_{6}, \delta$, ppm): $61.9,113.9,124.6,124.8,127.0,129.6,148.1$. Mass: $m / z=150.09133$ (experimental), 149.0841 (calculated). Melting point: $38^{\circ} \mathrm{C}$

c) Preparation of $\mathrm{N}$-acetyl-4-aminomethylcinnamyl alcohol from 4-aminocinnamyl alcohol. 4-aminocinnamyl alcohol (2.01 g, $13.4 \mathrm{mmol})$ was mixed with methanol $(30 \mathrm{ml})$ in a two neck round bottom flask under nitrogen atmosphere. Acetic anhydride $(5.5 \mathrm{~g}, 5 \mathrm{ml}, 53.6$ mmol) was added to the reaction mixture. The mixture was stirred overnight, evaporated and purified via column chromatography using silica gel and $10 \%$ ethyl acetate/petroleum ether as eluent. The $100 \%$ purified compound was obtained in $80 \%$ yield. The specifications were as follow: ${ }^{1} \mathrm{H}$ NMR (400 MHz, DMSO-d $\left.6, \delta, p p m\right): 2.03(\mathrm{~s}, 3 \mathrm{H}), 4.09(\mathrm{t}, 2 \mathrm{H}), 4.82(\mathrm{t}, 1 \mathrm{H})$ $6.26(\mathrm{td}, 1 \mathrm{H}, J=16 \mathrm{~Hz}), 6.47(\mathrm{~d}, 1 \mathrm{H}, J=16 \mathrm{~Hz}), 7.33(\mathrm{~d}, 2 \mathrm{H}, J=8 \mathrm{~Hz}), 7.53(\mathrm{~d}, 2 \mathrm{H}, J=8$ Hz), 9.94 (s, 1H). ${ }^{13} \mathrm{C}$ NMR (100 MHz, DMSO-d 6 , $\left.\delta, p p m\right): 23.9,61.6,118.9,126.4,128.2$, 
129.1, 131.2, 138.4, 168.1. Mass: $m / z=192.10182$ (experimental), 191.0946 (calculated). Melting point: $135^{\circ} \mathrm{C}$

d) Preparation of $N, N^{\prime}$-diacetyl-4,4'-diaminostilbene from $N$-acetyl-4-aminocinnamyl alcohol using Grubb's catalyst. N-acetyl-4-aminocinnamyl alcohol (1 g, $5.2 \mathrm{mmol}$,) and Grubb's second generation catalyst (5 mole percent, $0.27 \mathrm{mmol}, 233 \mathrm{mg}$ ) was taken in a round bottom flask followed by addition of $30 \mathrm{ml}$ THF under nitrogen atmosphere. The mixture was refluxed at $70{ }^{\circ} \mathrm{C}$ for $24 \mathrm{~h}$. The solvent was evaporated and the compound was separate by column chromatography using silica gel and $10 \%$ ethyl acetate/petroleum ether. The compound was obtained in $30 \%$ yield (collected), however the conversion was determined as ca. $100 \%$ by NMR studies. The specifications were as follow: ${ }^{1} \mathrm{H}$ NMR (400 MHz, DMSO-d 6 , $\delta, p p m): 2.05$ (s, 3H), $7.06(\mathrm{~s}, 1 \mathrm{H}), 7.49$ (d, 2H, $J=8 \mathrm{~Hz}), 7.57$ (d, 2H, $J=$ $8 \mathrm{~Hz}), 9.98$ (s, 1H). ${ }^{13} \mathrm{C}$ NMR (100 MHz, DMSO-d $\left.6, \delta, p p m\right): 24.5,119.5,127.0,127.1$, 132.5, 139.1, 168.7. Mass: $m / z=295.14403$ (experimental), 294.1368 (calculated). Melting point: $218{ }^{\circ} \mathrm{C}$

e) Preparation of DAS from $N, N^{\prime}$-diacetyl-DAS. N,N'-diacetyl-DAS $(0.25 \mathrm{~g}, 0.85 \mathrm{mmol})$ was mixed with methanol $(5 \mathrm{ml})$ in a two neck round bottom flask under nitrogen. $\mathrm{HCl}$ conc $(1.5 \mathrm{ml})$ was added and the mixture was stirred for $6 \mathrm{~h}$. The solvent was evaporated under vacuum followed by the addition of ammonia solution and then extracted using ethyl acetate 3 times $(10 \mathrm{ml})$. The collected ethyl acetate organic layer was dried over $\mathrm{MgSO}_{4}$, and it was then evaporated. The compound was obtained in $82 \%$ yield. The specifications were as follow: ${ }^{1} \mathrm{H}$ NMR (400 MHz, DMSO-d 6 , $\left.\delta, \mathrm{ppm}\right): 5.15$ (s, 4H), 6.56 (d, 2H, J=8 Hz), 6.74 (s, 2H), $7.20(\mathrm{~d}, 4 \mathrm{H}, J=8 \mathrm{~Hz}) .{ }^{13} \mathrm{C}$ NMR $\left(100 \mathrm{MHz}, \mathrm{DMSO}-\mathrm{d}_{6}, \delta, \mathrm{ppm}\right): 114.0,123.8,125.8$, 126.8, 147.7. Mass: $m / z=211.12286$ (experimental), 210.1157 (calculated). Melting point: $207^{\circ} \mathrm{C}$ 
f) Preparation of EDDA from DAS. DAS (0.1 g, $0.48 \mathrm{mmol})$ and $10 \% \mathrm{Pd} / \mathrm{C}(0.22 \mathrm{~g})$ was mixed with methanol $(5 \mathrm{ml})$ in a two neck round bottom flask and $\mathrm{H}_{2}$ gas was bubbled into the mixture while stirring. After $5 \mathrm{~h}$ the reaction mixture turned pink from orange. The reaction mixture was filtered and solvent was evaporated to get shiny pinkish crude product in $99 \%$ yield which was recrystallized using ethanol to get pink colored crystal. The specifications were as follow: ${ }^{1} \mathrm{H}$ NMR (400 MHz, DMSO-d 6 , $\left.\delta, \mathrm{ppm}\right): 2.61(\mathrm{~s}, 4 \mathrm{H}), 4.79$ (s, 2H), $6.49(\mathrm{~d}, 2 \mathrm{H}, J=8 \mathrm{~Hz}), 6.85(\mathrm{~d}, 2 \mathrm{H}) .{ }^{13} \mathrm{C}$ NMR (100 MHz, DMSO-d 6 , $\left.\delta, p p m\right): 37.1$, 113.9, 128.7, 129.0, 146.3. Mass: $m / z=213.14217$ (experimental), 212.1313 (calculated). Melting point: $137^{\circ} \mathrm{C}$

\subsubsection{PAAs and PIs syntheses}

Poly(amic acid)s (PAAs) are synthesized by a reaction of prepared diamines such as DAS with equimolar amounts of dianhydrides as shown in Scheme 2. The general procedure for the synthesis of PAA is as follows. DAS (0.252 $\mathrm{g}, 1.2 \mathrm{mmol})$ was dissolved in DMAc (2.4 ml, $0.5 \mathrm{M})$ in a $10 \mathrm{~mL}$ flask under nitrogen atmosphere. Dianhydrides such as CBDA $(0.235 \mathrm{~g}$, $1.2 \mathrm{mmol})$, PMDA (0.261 g, $1.2 \mathrm{mmol})$, BPDA (0.353 g, $1.2 \mathrm{mmol})$, BTDA (0.387 g, 1.2 mmol), OPDA (0.372 g, $1.2 \mathrm{mmol})$ and DSDA (0.430 g, $1.2 \mathrm{mmol})$ were then added into the diamine solution which produced a yellowish solution. The reaction mixture was vigorously stirred by a mechanical stirrer with a propeller at room temperature for $48 \mathrm{~h}$ to yield a viscous PAA solution. The PAA solution was diluted by suitable amount of DMAc, and then added dropwise into water/methanol/acetone to precipitate as solid fibrils PAA which were collected by filtration, washed thoroughly with warm water and dried in a vacuum. PAA film of thickness $30-45 \mu \mathrm{m}$ was obtained by dissolving polymer fibrils in DMAc/DMF forming a yellow solution, poured on a silicon wafer / aluminum plate by spin coating ( spin rate $=100$ rpm for $2 \mathrm{~min}, 200 \mathrm{rpm}$ for $2 \mathrm{~min}, 500 \mathrm{rpm}$ for $1 \mathrm{~min}$, MS-A100 Spincoater, Misaka Co., Ltd.) and dried by heating over hot plate. Polyimide (PI) films were obtained by stepwise 
thermal imidization of the PAAs film in an oven for $1 \mathrm{~h}$ each at $100,150,200$ and $250{ }^{\circ} \mathrm{C}$, respectively, under vacuum. Similar procedure was repeated to get PAAs and PIs using EDDA diamine and different dianhydride.

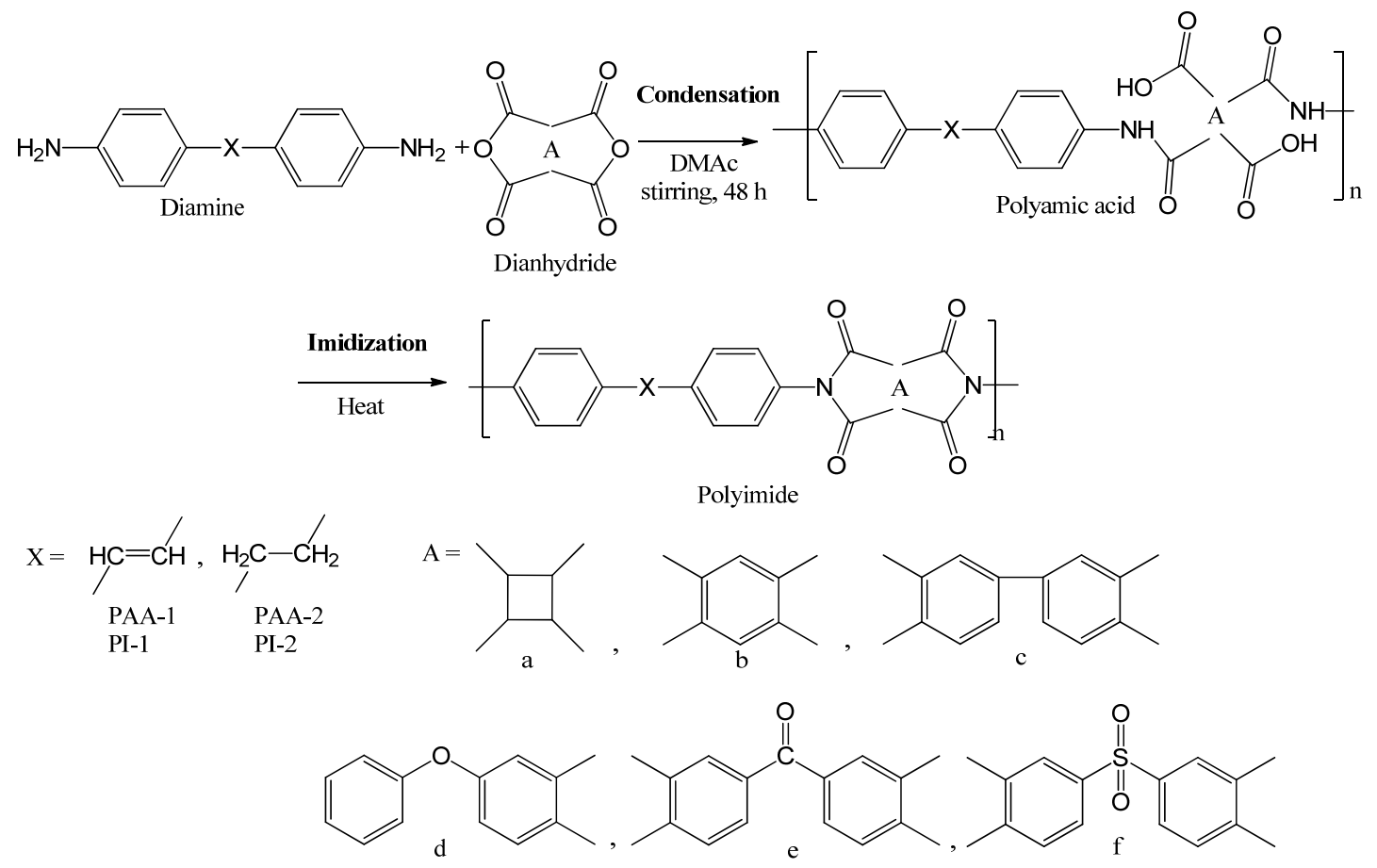

Scheme 2. Synthesis of bio-based PAAs and PIs from 4ACA derived monomers DAS and EDDA.

\section{Results and Discussion}

\subsection{Monomer Synthesis}

Olefin metathesis enables the redistribution of fragments of alkenes by scission and regeneration of carbon-carbon double bonds ${ }^{[26]}$. In particular, Grubbs' catalysts are airtolerant and compatible with a wide range of solvents ${ }^{[27-31]}$. We developed a novel synthesis route for aromatic diamines using Grubbs olefin metathesis reaction with the 4ACA derivative which is bioavailable by microbial deamination using recombinant Escherichia coli to possess the phenylalanine ammonia lyase activity ${ }^{[25,32-34]}$.

Initially, we tried to prepare DAS directly from the 4ACA metathesis reaction, but the reaction did not proceed smoothly. Then, we protected the amine group and reduced the 
carboxyl group to alcohol, and then started a metathesis reaction. In order to reduce carboxyl readily, the corresponding carboxylic acid was esterified by methanol in the presence of TMSCl. $\mathrm{LiAlH}_{4}$ was utilized to reduce methyl ester to alcohol. The product 4aminocinnamyl alcohol was purified by repeated column chromatography. The product purity was only $95 \%$ due to the presence of inseparable impurities, which were removed in the next step of the process. The free amine group of methyl-4-aminocinnamyl alcohol was acetylated using acetic anhydride to avoid it from interfering in Grubbs olefin metathesis. The resulting $\mathrm{N}$-acetyl-4-aminocinnamyl alcohol was used for olefin metathesis along with Grubbs $2^{\text {nd }}$ generation catalyst and N,N'-deacetyl-DAS was successfully prepared with moderate yield. The free diamine monomer DAS was prepared by deacetylation using $\mathrm{HCl}$ in methanol followed by neutralization by ammonia. The diamine EDDA was prepared from DAS by reducing the double bond using $\mathrm{Pd} / \mathrm{C}$ and $\mathrm{H}_{2}$. The structures of all intermediates were confirmed using ${ }^{1} \mathrm{H}$ NMR, ${ }^{13} \mathrm{C}$ NMR and FT-IR (Figures S1, S2 and S3).

Table 1: The yield, observation during polymerization, inherent viscosity $\left(\eta_{\text {inh }}\right)$, molecular weight, and film properties of PAAs.

\begin{tabular}{|c|c|c|c|c|c|c|}
\hline Polymer & Yield (\%) & $\begin{array}{c}\eta_{\text {inh }}{ }^{a} \\
(d L / g)\end{array}$ & $M_{\mathbf{n}}^{\mathbf{b}}$ & $M_{\mathrm{w}}^{\mathbf{b}}$ & $\mathbf{P D I}^{\mathbf{b}}$ & $\begin{array}{c}\text { Film } \\
\text { property }\end{array}$ \\
\hline PAA-1a & 96 & 6.62 & $2.50 \times 10^{5}$ & $4.04 \times 10^{5}$ & 1.62 & Flexible \\
\hline PAA-2a & 94 & 0.52 & $3.07 \times 10^{5}$ & $4.71 \times 10^{5}$ & 1.53 & Flexible \\
\hline PAA-1b & 96 & 0.54 & $1.72 \times 10^{5}$ & $2.21 \times 10^{5}$ & 1.29 & Flexible \\
\hline PAA-1c & 98 & 1.04 & $2.48 \times 10^{5}$ & $3.82 \times 10^{5}$ & 1.57 & Flexible \\
\hline PAA-2c & 98 & 0.48 & $2.35 \times 10^{5}$ & $3.84 \times 10^{5}$ & 1.63 & Flexible \\
\hline PAA-1d & 90 & 0.41 & $2.22 \times 10^{5}$ & $3.23 \times 10^{5}$ & 1.48 & Flexible \\
\hline PAA-1e & 91 & 0.51 & $1.83 \times 10^{5}$ & $2.95 \times 10^{5}$ & 1.61 & Flexible \\
\hline PAA-1f & 92 & 0.49 & $2.43 \times 10^{5}$ & $3.73 \times 10^{5}$ & 1.53 & Flexible \\
\hline PAA- $1 f^{c}$ & 91 & 0.53 & $2.82 \times 10^{5}$ & $4.30 \times 10^{5}$ & 1.52 & Flexible \\
\hline PAA- $1 f^{d}$ & 92 & 0.55 & $2.86 \times 10^{5}$ & $4.42 \times 10^{5}$ & 1.54 & Flexible \\
\hline PAA-2f & 92 & 0.41 & $2.15 \times 10^{5}$ & $3.27 \times 10^{5}$ & 1.51 & Flexible \\
\hline
\end{tabular}




\subsection{Polymer Syntheses}

PAAs were prepared by polycondensation of the prepared diamine of DAS or EDDA with stoichiometric amounts of the dianhydride CBDA, PMDA, BTDA, OPDA, BPDA, or DSDA (Scheme 2). The resulting PAAs were abbreviated as PAA-1a, PAA-1b, PAA-1c, PAA-1d, PAA-1e, and PAA-1f for DAS-based PAAs, and PAA-2a, PAA-2c, and PAA-2f for EDDAbased PAAs as shown in Table 1. The structures of the PAAs were confirmed by NMR study and conversion to PI was confirmed by IR spectroscopy (see Figures 1, 2 and 3 in Ref 38).

Highly viscous solutions were obtained after polymerization for each case except for PAA1a, which showed gel formation due to its ultrahigh viscosity. The weight-average molecular weight $\left(M_{\mathrm{w}}\right)$, the number average molecular weight $\left(M_{\mathrm{n}}\right)$ and the molecular weight distribution (PDI) were determined using GPC by dissolving PAAs in a suitable amount of DMF and the results are summarized in Table 1. PAAs exhibited high molecular weights of $2.2 \times 10^{5}-4.4 \times 10^{5} \mathrm{~g} / \mathrm{mol}$ for $M_{\mathrm{w}}$ and $1.7 \times 10^{5}-2.8 \times 10^{5} \mathrm{~g} / \mathrm{mol}$ for $M_{\mathrm{n}}$ and PDI ranged from 1.29 to 1.61 . Inherent viscosities of PAA solutions were determined at a concentration of 0.5 $\mathrm{g} / \mathrm{dL}$ and were found to range from 0.41 to $6.62 \mathrm{dL} / \mathrm{g}$ at $30{ }^{\circ} \mathrm{C}$ thereby confirming the high molecular weights of the PAAs (Table 1). Of all the bio-based PAAs, PAA-1a formed a gel after polymerization and showed the highest viscosity possibly due to the aliphatic cyclobutane ring of CBDA. Carboxylic acid attached to the CBDA ring in PAA-1 has a higher reactivity than an aromatic acid, occasionally causing the addition of $\mathrm{COOH}$ to the central double bond of stilbene moiety in PAA-1a, resulting in cross-linking of the polymer chains. If the reaction occurred with only $1 \%$ probability, the viscosity would be increased. PAA films were then cast from the DMAc solution by spin-coating and evaporating the solvent at $60-70{ }^{\circ} \mathrm{C}$ (Figure 1). DAS-based PAA films were yellow/orange colored while EDDA-based films were colorless to light yellow. The PI films were obtained by stepwise thermal imidization of PAA at $100,150,200$, and $250{ }^{\circ} \mathrm{C}$ for $1 \mathrm{~h}$ at each step in a vacuum 
oven. The film color changed from yellow to dark orange after imidization due to more efficient charge transfer between the diamine-based benzenes compared to the benzoic amic acids, leading to the color change in resulting benzimides ${ }^{[35]}$. The complete imidization was confirmed by FT-IR spectra. The PIs were represented as PI-1a, PI-2a, PI-1b, PI-1c, PI-2c, PI-1d, PI-1e, PI-1f and PI-2f.

a)
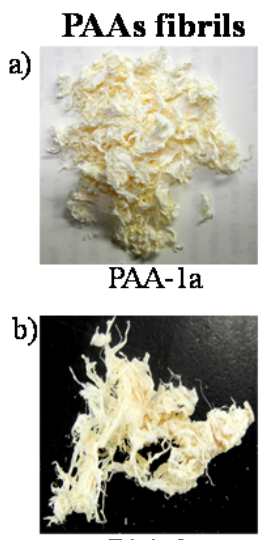

PAA-lc

c)

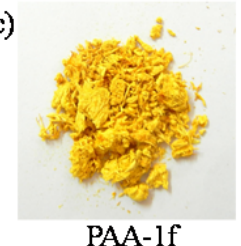

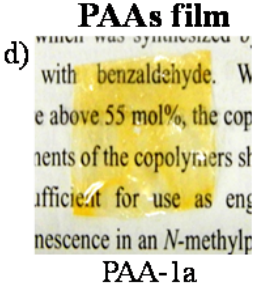

e) with benzaldehyde. Whe above 55 mol\%, the copols ents of the copolymers shov ficient for use as engin escence in an $N$-methylpyr length of $3 \mathrm{~m}$. Oriente f $75 \mathrm{~mol} \%$ itted polariz PAA-lc

f) which was synthesized by with benzaldehyde. Wl e above $55 \mathrm{~mol} \%$, the copc nents of the copsiymers shi ufficient for use as engi nescence in an $\mathrm{N}$-methylpy PAA-lf

\section{PIs film}

g) ${ }^{3} \mathrm{C}$ NMR, (Bruker To using DMSO- $d_{6}$ as Elmer), Ultraviolet-vis Elmer, Lambda 25 eter) at room temp

PI-la

h) in Elmer), Ultravio

n Elmer, Lambd meter) at room

am spectral I PI-lc

i) lacement of met ners, polyimides th high thermal ies also have the I

PI-lf

Figure 1. PAAs fibrils [(a) PAA-1a, (b) PAA-1c and (c) PAA-1f], PAAs film [(d)PAA-1a, (e) PAA-1c and (f) PAA-1f] and PIs [(g) PI-1a, (h)PI-1c and (i) PI-1f]

\subsection{Solubility}

The solubility of all the prepared polymers was investigated in various solvents as shown in Table S1. The solubility of the polymers was tested by dissolving them in three groups of solvents at room temperature and at $50{ }^{\circ} \mathrm{C}$. For those solvents whose boiling point was below $50{ }^{\circ} \mathrm{C}$ the solubility was checked at room temperature and at their boiling point. The three groups of solvents were: (A) nonpolar solvents such as hexane, benzene, toluene, dichloromethane (DCM), chloroform and diethyl ether, (B) polar protic solvents such as 
distilled water, methanol, ethanol, and concentrated sulfuric acid, and (C) polar aprotic solvents such as acetone, acetonitrile, ethyl acetate, THF, DMF, DMAc, NMP and DMSO. All of the PAAs prepared here were only soluble in polar aprotic solvents such NMP, DMAc, DMF, and DMSO at room temperature. It was found that DAS-derived PIs were insoluble even at $50{ }^{\circ} \mathrm{C}$ in all of the solvents shown above, while EDDA-derived PIs were soluble in conc. $\mathrm{H}_{2} \mathrm{SO}_{4}$.

\subsection{Thermal Properties}

\subsubsection{Thermogravimetric analysis (TGA)}

Thermogravimetric analysis (TGA) was utilized in order to investigate the thermal degradation of PIs. TGA was carried out under nitrogen atmosphere at a heating rate of 10 ${ }^{\circ} \mathrm{C} / \mathrm{min} . T_{\mathrm{d} 5}$ and $T_{\mathrm{d} 10}$ represents the $5 \%$ and $10 \%$ weight-loss temperatures, respectively, and the results are summarized in Table 2 and shown in Figure 2. The $T_{\mathrm{d} 5}$ values ranged between 397-550 ${ }^{\circ} \mathrm{C}$ while $T_{\mathrm{d} 10}$ ranged between 406 and $600{ }^{\circ} \mathrm{C}$, which indicates a high degree resistance to thermal degradation. DAS-based PIs such as PI-1a, PI-1c, and PI-1f showed higher $T_{\mathrm{d} 5}$ and $T_{\mathrm{d} 10}$ values compared to their respective EDDA-based PIs such as PI-2a, PI-2c and PI-2f due to the extended conjugation in DAS-based PIs. PI-1d showed the highest $T_{\mathrm{d} 10}$ value of $600{ }^{\circ} \mathrm{C}$, while CBDA-derived PIs such as PI-1a and PI-2a showed $T_{\mathrm{d} 10}$ values less than $500{ }^{\circ} \mathrm{C}$ since they had fewer aromatics (i.e. benzene rings) than the others. PIs prepared here showed higher $T_{\mathrm{d} 10}$ values and high degree of thermal resistance than conventional biobased polymers reported thus far. Changing the atmosphere from pure nitrogen to air did not significantly affect the stability of the PIs since air contains much more nitrogen than oxygen. The PIs maintained their stability towards oxidative thermal degradation in nitrogen and air. However, $T_{\mathrm{d} 10}$ was found to drop by $20-50{ }^{\circ} \mathrm{C}$ under a pure oxygen atmosphere due to high

oxidative thermal degradation. Representative results of the TGA in different atmosphere of PI-1f are shown in Figure 2B. Overall, PIs showed good thermal stability under nitrogen, air 
and oxygen atmospheres. TGA were carried out upto $650{ }^{\circ} \mathrm{C}$ as $\mathrm{th}$ is temperat ure is high enough to evaluate the thermal st abil it y. However, TGA upt o $800{ }^{\circ} \mathrm{C}$ was al so carried out for PI-1f to evaluate the residual weight which was found to be near 1 y $20 \%$.

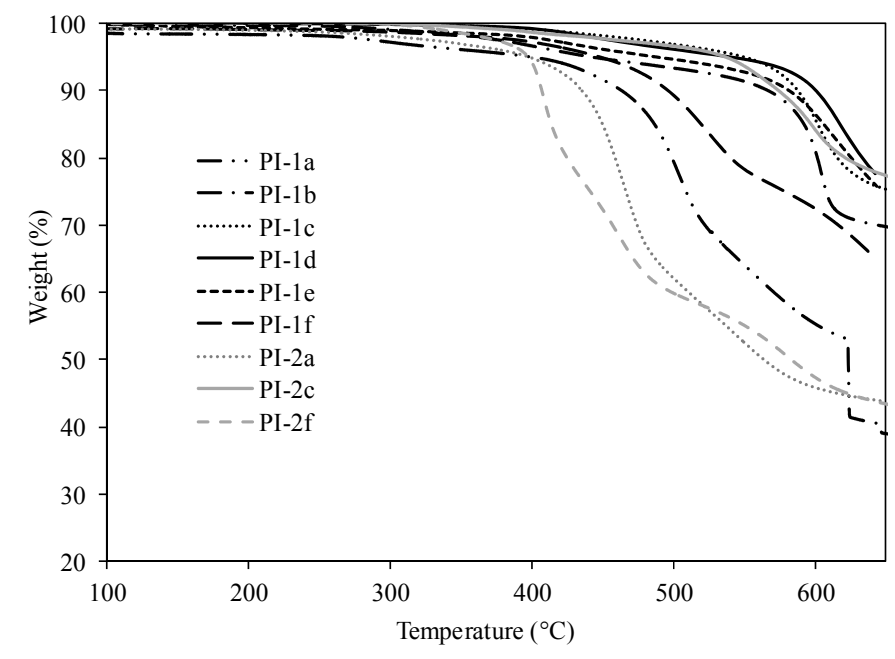

(A)

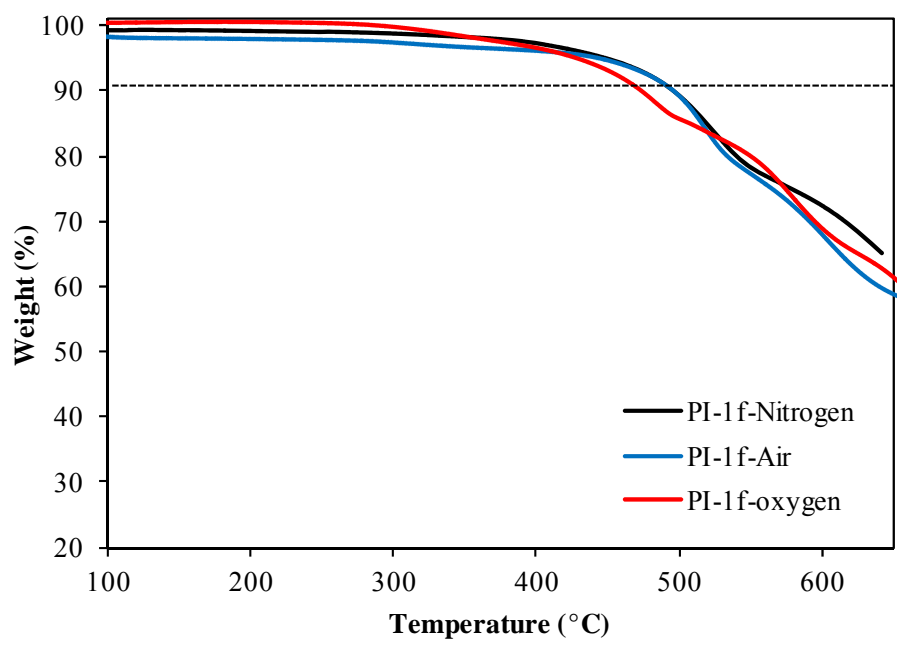

(B)

Figure 2. TGA curves of PI fil ms mea sured under a nit rogen at mosphere (A) and TGA curves of PI-1f in different at mosphere (B) at a heat ing rate of $10{ }^{\circ} \mathrm{C} / \mathrm{min}$

\subsubsection{Differential scanning calorimetry (DSC)}


Differential scanning calorimetry (DSC) was used to determine the $T_{\mathrm{g}}$ values of the PIs under a nitrogen atmosphere and the data are summarized in Table 2. The backbone structure of dianhydride plays an important role in the $T_{\mathrm{g}}$ values of the PIs ${ }^{[36,37]}$. The $T_{\mathrm{g}}$ values of PI-1b and PI-1e were determined to be $330{ }^{\circ} \mathrm{C}$ and $250{ }^{\circ} \mathrm{C}$, respectively. None of the PIs had $T_{\mathrm{g}}$ values below $350^{\circ} \mathrm{C}$, meaning that they could not show $T_{\mathrm{g}}$ values due to their decomposition temperature was lower than $T_{\mathrm{g}}$. The charge transfer from the electron rich bio-derived diamine to the electron deficient dianhydride and the high stability of the 5-membered imide ring due to extended $n-\pi$ conjugation between the carbonyl group and the lone pair of nitrogen atom could be the reasons for the high $T_{\mathrm{g}}$ values. Materials with high $T_{\mathrm{g}}$ values are suitable for application as super-engineering plastics.

Table 2. Thermo-mechanical properties of bio-based PIs

\begin{tabular}{|c|c|c|c|c|c|c|}
\hline & \multirow{2}{*}{$\begin{array}{c}\text { Tensile strength } \\
\text { at break } \\
(\mathrm{MPa})^{\mathrm{a}}\end{array}$} & \multirow{2}{*}{$\begin{array}{l}\text { Young's } \\
\text { modulus } \\
(\text { GPa) }\end{array}$} & \multirow{2}{*}{$\begin{array}{c}\text { Elongation at } \\
\text { break } \\
(\%)^{\mathrm{a}} \\
\end{array}$} & \multirow{2}{*}{$\underset{\left({ }^{\circ} \mathrm{C}\right)^{b}}{T_{\mathbf{g}}}$} & \multicolumn{2}{|c|}{ TGA $\left({ }^{\circ} \mathrm{C}\right)^{\circ}$} \\
\hline & & & & & $T_{\mathrm{d} 5}$ & $T_{\mathrm{d} 10}$ \\
\hline PI-1a & ND & ND & ND & ND & 400 & 460 \\
\hline PI-2a & 24 & 2.27 & 1.1 & ND & 400 & 435 \\
\hline PI-1b & ND & ND & ND & 330 & 445 & 565 \\
\hline PI-1c & 60 & 2.3 & 2.6 & ND & 550 & 585 \\
\hline PI-2c & 70 & 2.82 & 2.5 & ND & 535 & 575 \\
\hline PI-1d & 54 & 2.4 & 2.2 & ND & 540 & 600 \\
\hline PI-1e & 65 & 4.3 & 1.5 & 250 & 490 & 580 \\
\hline PI-1f & 81 & 3 & 7.8 & ND & 445 & 500 \\
\hline$P I-1 f^{d}$ & 106 & 2.8 & 3.9 & ND & 440 & 500 \\
\hline PI- $1 f^{e}$ & 132 & 2.4 & 5.6 & ND & 440 & 495 \\
\hline PI-2f & ND & ND & ND & ND & 395 & 405 \\
\hline Kapton $^{\mathrm{TM}}$ & 120 & 0.3 & 15.8 & ND & 430 & 555 \\
\hline
\end{tabular}

${ }^{a}$ Tensile strength at break, Young's modulus, and elongation at break were measured using tensiometer at room temperature, ${ }^{\mathrm{b}} T_{\mathrm{g}}$ referring to glass transition temperature was measured by $\mathrm{DSC}$ at a heating rate of $10{ }^{\circ} \mathrm{C} / \mathrm{min}$ under $\mathrm{N}_{2}$ atmosphere. ${ }^{\mathrm{c}} T_{\mathrm{d} 5}, T_{\mathrm{d} 10}$ referring to temperatures at $5 \%$ and $10 \%$ weight loss, respectively, which were measured using TGA at a heating rate of $10^{\circ} \mathrm{C} / \mathrm{min}$ under $\mathrm{N}_{2}$, . ND refers to not determined., ${ }^{\mathrm{d}}$ Polymerization time is $8 \mathrm{~h}$, ${ }^{\mathrm{e}}$ Polymerization time is $24 \mathrm{~h}$.

\subsection{Mechanical Properties}


The mechanical properties such as tensile strength at break, Young's modulus, and elongation at break were determined using a tensiometer at an elongation speed of $0.5 \mathrm{~mm} / \mathrm{min}$ at room temperature. The results are summarized in Table 2. As the degree of elongation at break measures flexibility, PI-1f was found to be more flexible than the other PIs due the flexible and kinked sulfone unit in the DSDA-derived moiety. PI-1a and PI-1b prepared from DAS diamine and dianhydride PMDA and CBDA, respectively, were found to be brittle due to the rigidity of their dianhydride-derived moieties. The brittleness made it impossible to prepare PI films for tensile strength tests. The PI films had tensile strength at break values in the range of 54-132 $\mathrm{MPa}$, Young's moduli in the range of 2.3-4.3 GPa, and elongation at break values in the range of $1.5-7.8 \%$. Of all the films prepared here, the PI-1f film was the strongest and toughest. PI-1f prepared by long agitation for $24 \mathrm{~h}$ showed an increased tensile strength of $132 \mathrm{MPa}$, Young's modulus of $2.4 \mathrm{GPa}$, and elongation at break of $5.6 \%$. The tensile strength of PI-1f was found to be more than that of the commercially available, best known and extensively used polyimide $\operatorname{Kapton}^{\mathrm{TM}}$. Totally bio-based PI-1a was too brittle to be examined for its tensile properties due to its highly rigid dianhydride CBDA and diamine DAS. PI-2a was flexible enough but showed lower than expected mechanical properties.

\subsection{UV-vis absorbance}

UV-vis spectroscopy was carried out by dissolving suitable amounts of PAA in DMF. $\lambda_{\max }$ of the PAAs derived from DAS were found to be in the visible range due to the extended conjugation by unsaturation as expected in compounds containing the stilbene moiety. The $\lambda_{\max }$ ranged from 348 to $358 \mathrm{~nm}$ depending on the type of dianhydride used. However, complete saturation led to no extended conjugation in EDDA-derived PAAs and thus no absorbance in the visible region (Figure 3 ). The $\lambda_{\max }$ values of PAA-1b and PAA 1c (358 nm and $357 \mathrm{~nm}$ respectively) were found to be higher than those of other PAAs. The high values of $\lambda_{\max }$ could be due to the rigidity in the dianhydride structure and thus in their respective 
PAAs. The $\lambda_{\max }$ of PAA-1e was the lowest $(348 \mathrm{~nm}$ ) due to the presence of a carbonyl linker between the two phenyl rings in BTDA. The $\lambda_{\max }$ values of PAA-1d and PAA- $1 \mathrm{f}$ were both $354 \mathrm{~nm}$. Since the PIs were insoluble in any of the solvent PI films were used in order to determine the transmittance. Figure 4 shows the wavelength dependence of transmittance of the PI films, where the transmittance ranges from 38 to $72 \%$.

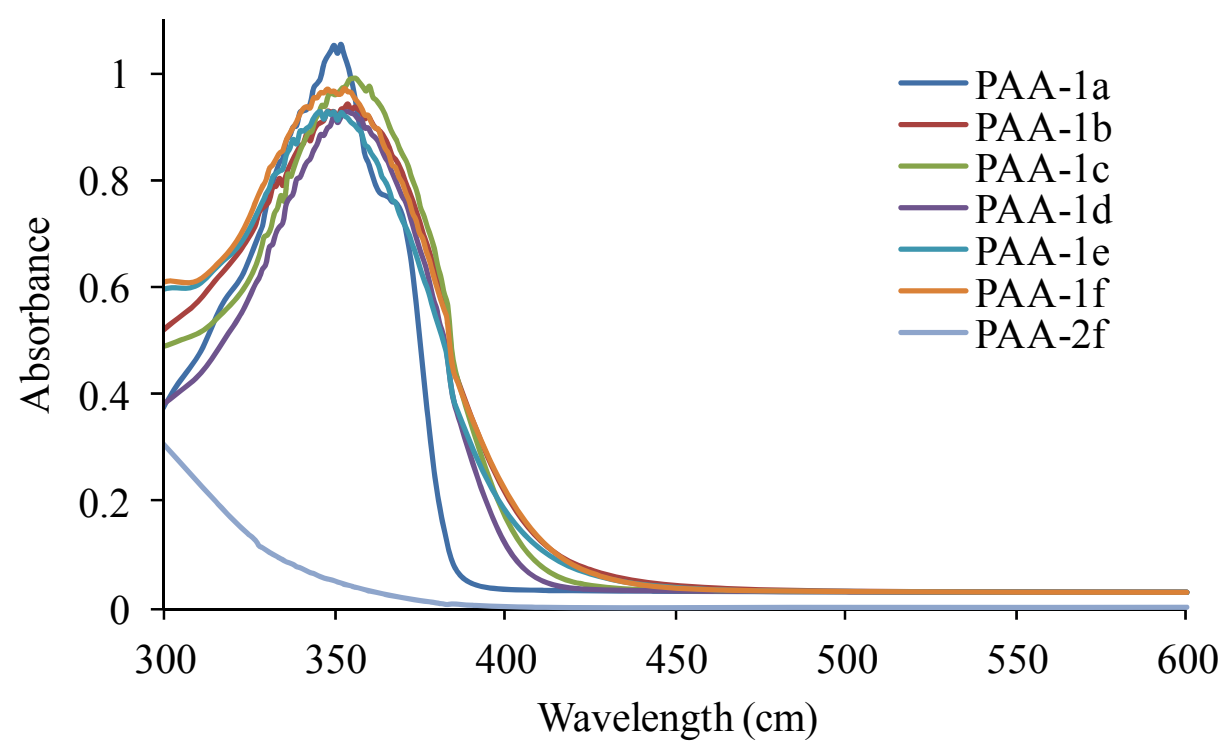

Figure 3. UV-vis spectra of PAAs showing the $\lambda_{\max }$ nearly about $354 \mathrm{~nm}$ for DAS based PAAs.

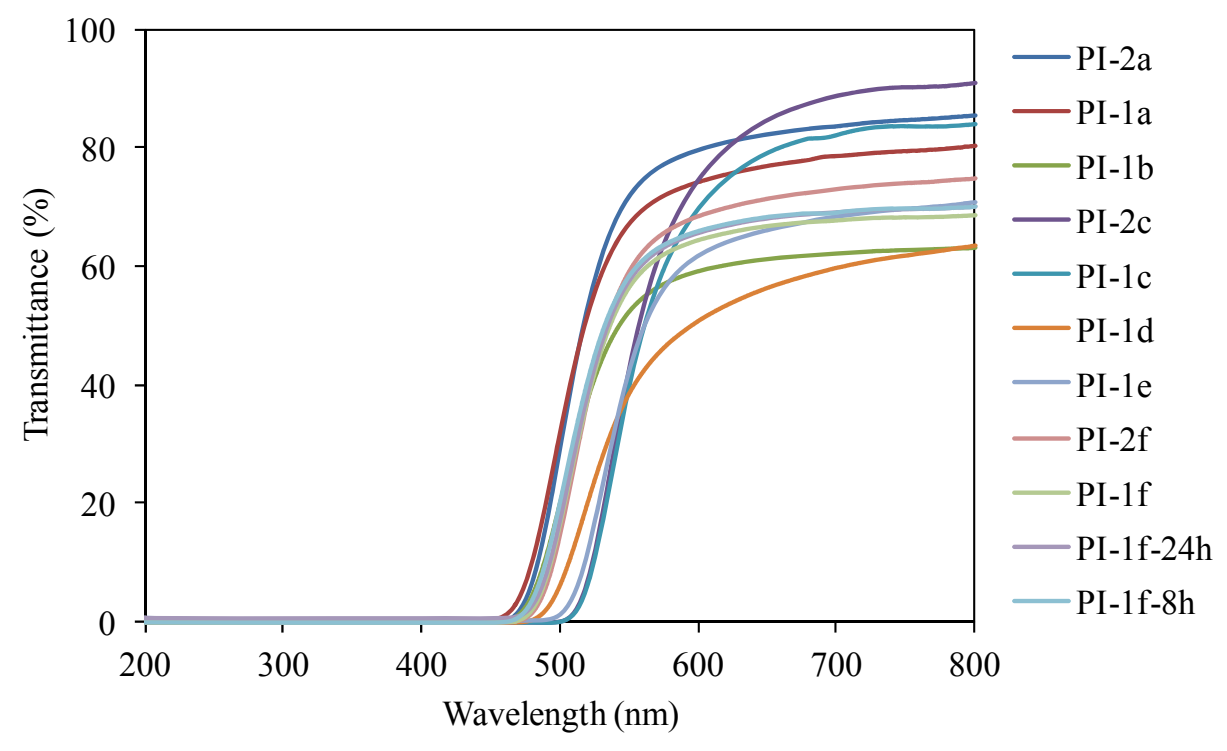


Figure 4. Transmittance spectra of total bio-based and semi bio-based PIs showing no transmittance upto $450 \mathrm{~nm}$.

\section{4.\#Conclusion}

A new method was employed to utilize the bio-derived material 4-aminocinnamic acid for the synthesis of diamine monomers of polyimides via a series of reactions utilizing Grubb's olefin metathesis. The prepared diamine was utilized and a series of different PAA and PI polymers were synthesized and found to be thermally and mechanically stronger than conventional polyimides. PI-1f prepared by $24 \mathrm{~h}$ polymerization showed higher mechanical properties than Kapton $^{\mathrm{TM}}$, which is a commercially available polyimide used extensively.

\section{Acknowledgement}

The research was financially supported by Advanced Low Carbon Technology Research and Development Program (JST ALCA, 5100270), Tokyo, Japan and MEXT.

\section{References}

(1) J. S. Golden, R. B. Handfield, US Department of Agriculture (http://www.biopreferred.gov/files/WhyBiobased.pdf).

(2) K. Okano, A. Kondo, H. Noda, Econ. Ind. 2006, 11, 43.

(3) M. Vert, Biomacromolecules. 2005, 6, 538-546. DOI: 10.1021/bm0494702.

(4) I. Taniguchi, Y. Kimura, Biopolymers. 2001, 3b, 431.

(5) T. Kaneko, M. T. Matsusaki, M. Hang, M. Akashi, Macromol. Rapid Commun. 2004, $25,673-677$.

(6) T. Kaneko, H. T. Tran, M. Matsusaki, M. Akashi, Chem. Mater. 2006, 18, 6220-6226.

(7) D. Kaneko, S. Kinugawa, K. Matsumoto, T. Kaneko, Plant Biotechnol. 2010, 27, 293-296. 
(8) S. Wang, D. Kaneko, K. Kan, X. Jin, T. Kaneko, Pure Appl. Chem. 2012, 84, 2559-2568.

(9) T. Kaneko, T. H. Thi, D. J. Shi, M. Akashi, Nat. Mater. 2006, 5, 966-970.

(10) D. Parker, J. Bussink, H. T. Van De Grampel, G. W. Wheatley, E. U. Dorf, E. Ostlinning, K. Reinking, F. Schubert, O. Jünger (2012). Polymers, High-Temperature. Ullmann's Encyclopedia of Industrial Chemistry.

DOI: 10.1002/14356007.a21_449.pub3.

(11) W. Thielemans, R. P. Wool, Biomacromolecules. 2005, 6, 1895-1905.

(12) P. Madhavamoorthi, Synth. Fibers. 2004, 33, 16-28.

(13) I. A. Ronava, M. Bruma, Struct. Chem. 2010, 21, 1013-1020.

(14) M. C. Choi, J. Wakita, C. S. Ha, S. Ando, Macromolecules 2009, 42, 5112-5120.

(15) H. Suzuki, Y. Ohnishi, Y. Furusho, S. Sakuda, S. Horinouchi, J. Biol. Chem. 2006, 281, 36944-36951.

(16) A. Noguchi, T. Kitamura, H. Onaka, S. Horinouchi, Y. Ohnishi, Nat. Chem. Biol. 2010, $6,641-643$.

(17) O. H. Johnson, D. E. Green, R. Pauli, J. Biol. Chem. 1994, 153, 37-47.

(18) J. van der Lee, Recl. Trav. Chim. Pays-Bas. 1926, 45, 674-709. DOI: $10.1002 / \mathrm{recl} .19260451002$

(19) F. D. Bellamy and K. Ou, Tetrahedron Letters. 1984, 25(8), 839-842. DOI:10.1016/S0040-4039(01)80041-1

(20) T. Kitazume, A. Tanaka, N. Takaya, A. Nakamura, S. Matsuyama, T. Suzuki, H. Shoun, Eur. J. Biochem. 2002, 269, 2075-2082.

(21) (a) J. F. Kane, M. J. Fiske, J. Bacteriol. 1985, 161, 963-966. DOI: 00219193/85/030963-04\$02.00/0. (b) M. J. MacDonald, B. D. Godwin, Biochem. Cell Biol. (2007), 85(3) 273-282. DOI: 10.1139/O07-018 
(22) B. Bibal, C. Mongin, D. M. Bassani, Chem. Soc. Rev. 2014, 43, 4179-4198. DOI: 10.1039/C3CS60366K. DOI: 10.1046/j.1432-1033.2002.02855.x

(23) S. Choi, S. H. Park, A. Y. Ziganshina, Y. H. Ko, J. W. Lee, K. Kim, Chem. Commun., 2003, 17, 2176-2177. DOI: 10.1039/B306832C

(24) M. Hussain, K. M. Khan, S. H. Ali, R. Parveen, W. S. Shim, Fibers and Polym. 2009, 10(4), 407-412. DOI 10.1007/s12221-009-0407-z

(25) P. Suvannasara, S. Tateyama, A. Miyasato, K. Matsumura, T. Shimoda, T. Ito, Y. Yamagata, T. Fujita, N. Takaya, T. Kaneko, Macromolecules. 2014, 47, 1586-1593. dx.doi.org/10.1021/ma402499m

(26) D. Astruc, New J. Chem. 2005, 29 (1), 42-56. DOI:10.1039/b412198h.

(27) R. H. Grubbs, (2003). Handbook of Metathesis (1st ed.). German: WileyVCH. ISBN 3-527-30616-1.

(28) R. H. Grubbs, T. M. Trnka, (2004) Ruthenium-Catalyzed Olefin Metathesis in "Ruthenium in Organic Synthesis" (S.-I. Murahashi, Ed.), Wiley-VCH, Germany.

(29) G. C. Vougioukalakis, R. H. Grubbs, Chem. Rev. 2010, 110 (3), 17461787. DOI:10.1021/cr9002424. PMID 20000700.

(30) T. M. Trnka, R. H. Grubbs, Accounts of Chem. Res. 2001, 34 (1), 1829. DOI:10.1021/ar000114f. PMID 11170353.

(31) J. Cossy, S. Arseniyadis, C. Meyer, (2010). Metathesis in Natural Product Synthesis: Strategies, Substrates and Catalysts (1st ed.). Germany: Wiley-VCH. ISBN 3-527$32440-2$.

(32) J. He, N. Magarvey, M. Piraee, L. C. Vining, Microbiology. 2001, 147, 2817-2829.

(33) R. A. Mehl, J. C. Anderson, S. W. Santoro, L. Wang, A. B. Martin, D. S. King, D. M. Horn, P. G. Schultz, et al. J. Am. Chem. Soc. 2003, 125, 935-939. 
(34) K. Yanai, N. Sumida, K. Okakura, T. Moriya, M. Watanabe, T. Murakami, Nat. Biotechnol. 2004, 22, 848-855.

(35) A. S. Mathews, I. Kim, C. S. Ha, Macromol. Res. 2007, 15, 114-128.

(36) M. Khan, G. Brunklaus, V. Enkelmann, H. W. Spiess, J. Am. Chem. Soc. 2008, 130, 1741-1748.

(37) S. Zhang, Y. Li, D. Yin, X. Wang, X. Zhao, Y. Shao, S. Yang, Eur. Polym. J. 2005, 41, 1097-1107. DOI: 10.1021/ja0773711.

(38) Structural investigation of poly(amic acid)s and polyimides from 4,4'-diaminostilbene, A. Kumar, S. Tateyama, K. Yasaki, Md. A. Ali, N. Takaya, R. Singh and T. Kaneko, Data in Brief "submitted". 


\section{Graphical abstract}

For

\section{Ultrahigh performance bio-based polyimides from}

\section{4,4'-diaminostilbene}

Amit Kumar ${ }^{1,3 \|}$, Seiji Tateyama ${ }^{1,4 \|}$, Katsuaki Yasaki ${ }^{1}$, Mohammad Asif Ali ${ }^{1}$, Naoki Takaya ${ }^{2,4}$, Rajeev Singh ${ }^{3}$ and Tatsuo Kaneko*, ${ }^{1,4}$

${ }^{1}$ School of Materials Science, Japan Advanced Institute of Science and Technology (JAIST), 1-1 Asahidai, Nomi-shi, Ishikawa, 923-1292, Japan

${ }^{2}$ Faculty of Life and Environmental Sciences, University of Tsukuba, Ibaraki, 305-8572, Japan

${ }^{3}$ Material/ Organometallics Laboratory, Department of Chemistry, ARSD College, University of Delhi-110021, India

${ }^{4}$ JST, ALCA

\| Equal contribution to this paper

*Email: kaneko@jaist.ac.jp, Telephone: +81-761-51-1633, Fax: +81-761-51-1635.

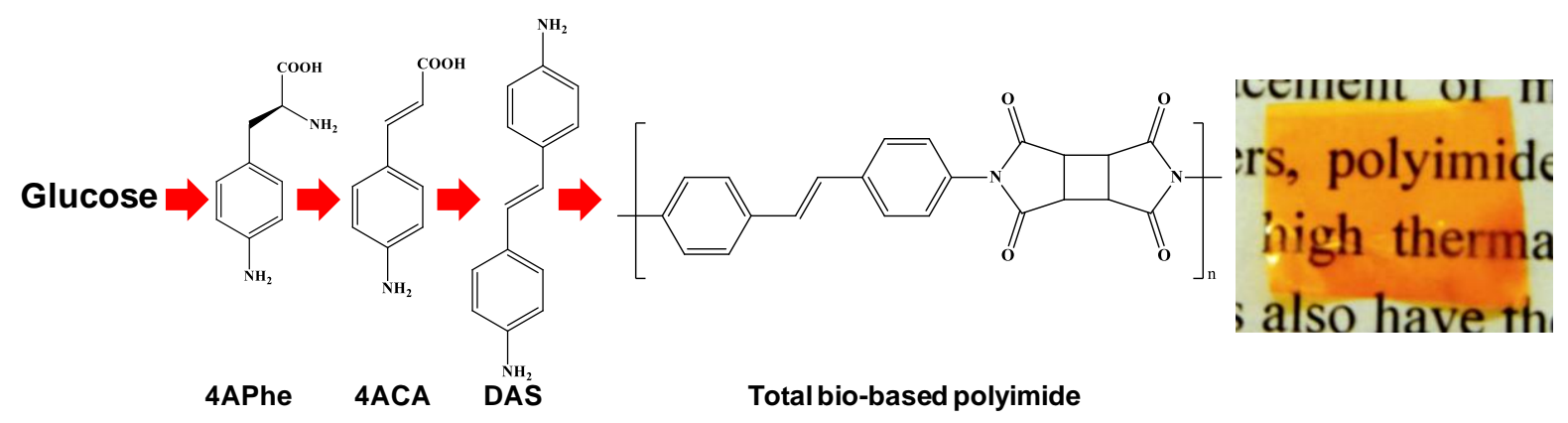

